\title{
Perfil eletroforético de proteínas séricas do sangue do cordão umbilical de cães
}

\author{
Electrophoretic profile of serum proteins from the umbilical chord blood of dogs
}

\author{
Aline Vieira Godoy ${ }^{1}$ Aureo Evangelista Santana ${ }^{2}$ Ana Paula Massae Nakage ${ }^{3}$ \\ Maria Luísa Buffo de Cápua ${ }^{4}$ Tiago Ladeiro de Almeida ${ }^{5}$
}

\section{RESUMO}

A importância do estudo do sangue do cordão umbilical (SCU) tem sido verificada pela presença de célulastronco hematopoéticas no SCU humano. O modelo experimental em cão tem propiciado informações importantes nos transplantes em humanos. Entretanto, apesar da importância do SCU e do modelo experimental em cães, não existem estudos sobre a eletroforese de proteínas séricas do cordão umbilical canino. No presente protocolo experimental, foi feita a colheita de SCU de 20 neonatos caninos, o qual foi utilizado para o fracionamento eletroforético de suas proteínas. Os valores médios absolutos obtidos para proteínas séricas totais, albuAmina, alfa, beta e gamaglobulinas no sangue do cordão umbilical de cães ao nascimento foram $3,09 \pm 0,59 ; 1,51 \pm 0,38 ; 0,87 \pm 0,17 ; 0,68 \pm 0,12$ e $0,03 \pm 0,01$ respectivamente. Todos os resultados apresentaram-se abaixo dos níveis reportados para animais adultos, devido à passagem das proteínas e suas frações ocorrerem principalmente através do colostro e pela imaturidade hepática. Em todos os traçados eletroforéticos do SCU de cães, foi observada uma pequena curva entre alfaglobulina 2 e betaglobulina 1, não relatada no soro de cães adultos. Portanto, neste experimento, foram observadas diferenças quantitativas no traçado eletroforético das proteínas séricas do SCU de cães, ao nascimento, diferindoos, neste particular, de cães em diferentes fases da vida póscolostral.

Palavras-chave: cordão umbilical, cães, eletroforese.

\section{ABSTRACT}

The importance of umbilical chord blood (UCB) study has been verified by the presence of hematopoietic stem cells in human UCB. The use of dogs as experimental model has provided usefull information for transplants in humans. However, despite the importance of UCB and dogs as experimental model, there are no studies concerning to the serum protein electrophoresis of the canine UCB. In this assay, UCB from 20 newborn dogs were collected, which was used for protein electrophoretic fractioning. The serum protein absolute medium values found for total proteins, albumine, alpha, beta and gamaglobulines in the UCB of newborn dogs where $3.09 \pm 0.59 ; 1.51 \pm 0.38 ; 0.87 \pm 0.17 ; 0.68 \pm 0.12$ and $0.03 \pm 0.01$, respectively. All values were presented bellow reported levels for adult animals, due to protein and its fractions passage mainly through the colostrum and due to hepatic immaturity. In all electrophoretic bandshifts from the canine UCB was observed a small curve between alphaglobulin 2 and betaglobulin 1, not reported in adult dogs. Therefore, in this assay quantitative differences were observed in the electrophoretic bandshift of serum proteins from dog's UCB at birth, differing them, in this particularly, from dogs in others post-colostral life stages.

Key words: umbilical cord, dogs, electrophoresis.

\section{INTRODUÇÃO}

A importância do estudo do sangue do cordão umbilical (SCU) tem sido verificada em trabalhos recentes que têm demonstrado a presença de células progenitoras hematopoéticas no SCU humano, representando uma fonte alternativa ao transplante

\footnotetext{
${ }^{1}$ Pós-graduação em Cirurgia Veterinária, Faculdade de Ciências Agrárias e Veterinárias (FCAV), Universidade Estadual Paulista (UNESP), Campus de Jaboticabal, Rua Tamandaré, 264, 18040-360, Sorocaba, São Paulo, Brasil. E-mail: alinevgodoy@yahoo.com.br). Autor para correspondência.

${ }^{2}$ FCAV, UNESP, Campus de Jaboticabal, Jaboticabal, São Paulo, Brasil.

${ }^{3}$ Centro Universitário Barão de Mauá, Ribeirão Preto, São Paulo, Brasil

${ }^{4}$ Pós-graduação em Medicina Veterinária, FCAV/UNESP, Campus de Jaboticabal, Jaboticabal, São Paulo, Brasil.

${ }^{5}$ Pós-graduação em Cirurgia Veterinária, FCAV/UNESP, Campus de Jaboticabal, Jaboticabal, São Paulo, Brasil.
} 
alogênico de medula óssea para reconstituição hematopoética (GLUCKMAN et al., 1989; BROXMEYER et al., 1989; VILMER et al., 1992; WAGNER et al., 1992).

Os modelos experimentais de transplantes de sangue periférico e medula óssea em cães têm propiciado informações pré-clínicas de extrema importância nos transplantes em humanos. A condução do protocolo com cães permite melhor estudo clínico, inúmeras facilidades na colheita de sangue, transfusão sangüínea e transplante de órgãos e tecidos (NAKAGE et al., 2003).

Em Medicina Veterinária, existem relatos escassos referentes às células do SCU de cães (NAKAGE et al., 2002; NAKAGE et al., 2003; NAKAGE et al., 2004; NAKAGE et al., 2005) e eqüídeos (GODOY, 2003).

As proteínas são compostos indispensáveis à vida, representando a base da estrutura de células, tecidos e órgãos. Funcionam como catalisadores enzimáticos nas reações bioquímicas, carreadores de muitos constituintes do plasma e na defesa orgânica como anticorpos (JAIN, 1993; KANEKO et al., 1997). Pelo significado biológico e múltiplas funções exercidas no sistema orgânico, a avaliação dos níveis séricos das proteínas totais e de suas frações (albumina, alfaglobulinas, betaglobulinas e gamaglobulinas), obtidas por eletroforese, representa um importante auxílio ao diagnóstico clínico (KANEKO et al., 1997).

O metabolismo e a quantidade de proteínas presentes no soro de animais neonatos podem sofrer influência de diversos fatores, dentre os quais devem ser destacados a ingestão do colostro e a idade. Ao nascimento, os animais domésticos exibem baixos teores protéicos e, após receberem o colostro, apresentam um aumento nas proteínas totais, devido à absorção intestinal de macromoléculas, incluindo as imunoglobulinas (BUTLER, 1969; FELDMAN et al., 2000).

As globulinas, geralmente, são separadas eletroforeticamente nas frações alfa, beta e gama, as quais contêm sub-frações com padrões de migração eletroforética similares. A concentração sérica de cada fração é determinada e comparada com os valores de referência de cada espécie. O eletroforetograma aporta informações sobre elevações e decréscimos nas concentrações séricas das diferentes frações protéicas. Alterações nos padrões das frações protéicas não são características de uma doença em particular, mas podem trazer importantes informações diagnósticas, quando usadas em conjunto com outros achados clínicos e laboratoriais (FELDMAN et al., 2000).
A eletroforese em gel de agarose tem sido utilizada amplamente em laboratórios de bioquímica clínica. Trata-se de técnica fundamentada na migração de partículas protéicas, eletricamente carregadas, em um campo elétrico e, no caso do soro sangüíneo, possibilita o fracionamento eletroforético de proteínas séricas em suas diferentes frações (KANEKO et al., 1997). Segundo Donkey \& Keay (1981), citado por KANEKO et al. (1997), o cão apresenta sete frações protéicas, incluindo albumina, alfaglobulinas (alfa $\mathrm{e}_{1}$ alfa $_{2}$ ), betaglobulinas (beta e beta $_{2}$ ) e gamaglobulinas ( gama ${ }_{1}$ e gama ${ }_{2}$ ). O traçado eletroforético das proteínas séricas de cães hígidos consiste no pico agudo da albumina, que migra primeiro em direção ao ânodo, seguida pela alfa e $_{1}$ alfa $_{2}$-globulinas, beta e beta $_{2}$ globulinas, gama e gama $_{2}$-globulinas (KANEKO et al., 1997).

A determinação das concentrações séricas de proteínas vem se tornando um procedimento valioso para o entendimento dos processos fisiopatológicos, sendo utilizada em animais sadios e doentes. Pesquisas recentes têm evidenciado que a qualificação e a quantificação de proteínas séricas podem subsidiar o diagnóstico e trazer valiosas informações prognósticas e de monitoramento de doenças (ECKERSALL, 2000).

Conhecendo-se as concentrações das proteínas séricas totais e da albumina, pode-se determinar, por diferença, o valor absoluto das globulinas. Pode-se, ainda, estabelecer a relação albumina: globulina (SEVELIUS \& ANDERSSON, 1995).

Os valores para proteínas totais, albumina, alfa, beta e gamaglobulinas em cães adultos saudáveis já estão bem caracterizados (BARSANTI et al., 1977; KEAY, 1982; HARRUS, 1996), no entanto há raríssimas citações referentes a esses valores para cães neonatos, antes da ingestão do colostro.

Entretanto, apesar da importância do sangue do cordão umbilical como fonte de células hematopoéticas progenitoras, e também da importância das informações adquiridas através da eletroforese e do modelo experimental em cães, não existem estudos sobre a eletroforese de proteínas séricas do cordão umbilical canino. Portanto, o ensaio em questão foi idealizado com o objetivo principal de caracterizar o perfil eletroforético das proteínas do SCU de cães neonatos.

\section{MATERIAL E MÉTODOS}

O sangue do cordão umbilical foi colhido de 20 recém-nascidos, oriundos de nove ninhadas de cadelas diferentes, submetidas à cesariana junto ao 
Instituto de Obstetrícia e Reprodução de Cães e Gatos "Prof. Dr. Vicenti Borelli” do Hospital Veterinário "Governador Laudo Natel” da Faculdade de Ciências Agrárias e Veterinárias - Universidade Estadual Paulista (FCAV/UNESP), Campus de Jaboticabal (SP). O total de nascidos foi de 34 cães.

Após o nascimento, procedeu-se liberação do neonato, dos seus respectivos envoltórios placentários, clampeamento do cordão umbilical na porção justafetal com auxílio de duas pinças hemostáticas e, finalmente, secção do cordão umbilical e separação do neonato e placenta. Ato contínuo, a placenta de cada recém-nascido foi posicionada em plano elevado para que o SCU fluísse e fosse colhido por venipunção umbilical, com seringa de cinco $\mathrm{mL}$ sem anticoagulante.

Após a colheita, o sangue do cordão umbilical foi mantido em repouso durante 15 minutos e, a seguir, centrifugado para obtenção do soro. Após a dosagem das proteínas séricas totais, a alíquota de soro remanescente foi envasada e armazenada até o momento da análise eletroforética. As proteínas séricas totais do SCU foram avaliadas pelo método do Biureto, por meio de leitura colorimétrica em espectrofotômetro (Labquest).

O fracionamento eletroforético das frações protéicas do soro foi obtido de acordo com o procedimento que se segue. Após o preenchimento da cuba com 80ml de tampão tris, $\mathrm{pH} \mathrm{9,5} \mathrm{a} 4^{\circ} \mathrm{C}$, aplicaramse no filme de agarose alíquotas de $0,4 \mu \mathrm{L}$ de soro. Em seguida, o filme de agarose foi colocado em suporte apropriado com a extremidade onde foram colocadas as amostras voltadas para o pólo negativo. O “cassete” foi colocado de modo a apoiar-se na cuba, conectada a uma fonte (100 volts), durante 20 minutos. A seguir, o filme foi mergulhado em $200 \mathrm{~mL}$ de corante negro de amido, onde permaneceu por cinco minutos, seguido por mais cinco minutos no descorante a base de ácido acético a $5 \%$. O filme foi colocado em estufa, a $60^{\circ} \mathrm{C}$, até que ficasse completamente seco. Em seguida, passou por nova fase de descoloração com banhos sucessivos de ácido acético a 5\%, seguidos de nova secagem a $60^{\circ} \mathrm{C}$.

Uma vez obtido o traçado, caracterizado pela migração das frações protéicas (albumina, alfa, beta e gamaglobulinas) no gel de agarose foram realizadas leituras densitométricas através do programa SDS-60, cujos valores absolutos e relativos, de cada fração, foram finalmente obtidos.

Os dados obtidos para proteínas séricas totais, bem como para as frações protéicas (albumina, alfa, beta e gamaglobulinas) no SCU de cães, foram apresentados através de médias e desvios-padrão (SNEDECOR \& COCHRAN, 1987).

\section{RESULTADOS E DISCUSSÃO}

Os valores médios, absolutos e relativos, de proteínas séricas totais, albumina, alfa, beta e gamaglobulinas estão apresentados na tabela 1.

No presente experimento, os valores médios absolutos obtidos para proteínas séricas totais, albumina, alfa, beta e gamaglobulinas no sangue do cordão umbilical (SCU) de cães, ao nascimento, apresentaram-se abaixo dos níveis relatados em animais adultos (BARSANTI, 1977; KEAY, 1982; HARRUS, 1996), dado este que se encontra em conformidade com os achados de KUHL et al. (2000), que avaliaram o sangue periférico de cães desde o nascimento até os dois meses de idade.

Este valor reduzido de proteína sérica total no SCU deve-se principalmente às pequenas quantidades de gamaglobulinas encontradas no sangue de cães ao nascimento, antes da ingestão do colostro. Nos carnívoros domésticos, embora haja uma pequena passagem de IgG através da placenta, a maior parte é adquirida com a ingestão do colostro. A passagem transplacentária ocorre devido à placentação endoteliocorial dos cães, na qual o epitélio coriônico fica em contato com o endotélio dos capilares maternos (TIZARD, 1998). Os valores encontrados, neste ensaio, confirmam os relatos de BUTLER (1969) e FELDMAN et al. (2000), que referem à existência de baixos teores seroprotéicos nos animais domésticos ao nascimento.

Na avaliação do sangue periférico de cães, do nascimento até dois meses de idade, KUHL et al. (2000) relataram quantidades reduzidas de albumina, em comparação àquelas encontradas em cães adultos,

Tabela 1 - Valores absolutos e relativos, dos teores séricos de proteínas totais, albumina, alfa ${ }_{1}$, alfa $_{2}$, beta , $_{1}$, beta 2 e gamaglobulinas no sangue do cordão umbilical de cães, ao nascimento.

\begin{tabular}{lcc}
\hline & $\begin{array}{c}\text { Valores médios } \pm \\
\text { desvios-padrão }(\mathrm{g} / \mathrm{dL})\end{array}$ & $\begin{array}{c}\text { Valores relativos } \\
(\%)\end{array}$ \\
\hline Proteínas totais & $3,09 \pm 0,59$ & 100,00 \\
Albumina & $1,51 \pm 0,38$ & 48,87 \\
Alfaglobulina & $0,87 \pm 0,17$ & 28,15 \\
Alfa $_{1}$ & $0,51 \pm 0,11$ & 16,50 \\
Alfa $_{2}$ & $0,36 \pm 0,07$ & 11,65 \\
Betaglobulina $_{\text {Beta }}$ & $0,68 \pm 0,12$ & 22,00 \\
Beta $_{2}$ & $0,40 \pm 0,09$ & 12,94 \\
Gamaglobulina & $0,28 \pm 0,07$ & 9,06 \\
\hline
\end{tabular}


sendo que, no presente estudo, os valores encontrados corroboram esta afirmação.

Com relação aos valores relativos, experimentalmente a albumina e alfaglobulinas apresentaram médias maiores no SCU do que as encontradas no sangue periférico de cães adultos, por BARSANTI (1977), KEAY (1982) e HARRUS (1996). Os valores médios relativos de betaglobulinas apresentaram-se discretamente reduzidos com relação àqueles obtidos pelos autores supracitados. Houve diferença acentuada entre valores relativos de gamaglobulinas no SCU e aqueles verificados em soro de cães adultos, sendo que o valor de gamaglobulina deste estudo $(0,98 \%)$ foi dez vezes menor do que o valor médio encontrado pelos referidos autores (9,8\%).

A discrepância encontrada pode ser explicada pelo fato de que valores relativos menores de beta e gamaglobulinas ocorrem devido às regiões beta $_{2}$, gama ${ }_{1}$ e gama ${ }_{2}$ serem compostas principalmente por imunoglobulinas, como observado por KANEKO et al. (1997), e estas terem sua principal passagem através do colostro.

O sangue foi colhido observando-se as considerações anatomofisiológicas descritas por ZANCO (1998), sendo que não foram encontradas grandes diferenças quanto à dificuldade de colheita entre cesarianas ou partos normais, salvo o fato de que, em alguns partos normais, ocorria eliminação do filhote antes da sua respectiva placenta, e conseqüente rompimento do cordão umbilical, inviabilizando a colheita do sangue do referido cordão.

A diversidade racial dos animais não foi considerada como fator relevante na seleção dos mesmos, sendo que foram colhidas amostras de animais sem raça definida (SRD), Pit Bull, Buldog Inglês, Poodle, American Staffordshire Terrier, Cocker Spaniel e Rottweiler.

O método de eletroforese em gel de agarose mostrou-se eficiente para quantificar as proteínas séricas do SCU, conforme descrito por KANEKO et al. (1997) e FELDMAN (2000). Entretanto, em todos os traçados eletroforéticos deste estudo, foi observada

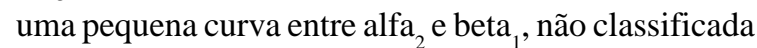
devido ao gel de agarose ser um material que permite a identificação de apenas 5 a 7 frações protéicas, e apesar de ser eficiente para esta tarefa, não é capaz de qualificar proteínas com peso molecular muito baixo (MATTEWS, 1982; KEAY, 1982).

A análise do achado e a identificação dessa possível fração protéica deverá ser objeto de um próximo estudo, no qual será utilizada a eletroforese em gel de poliacrilamida contendo dodecil sulfato de sódio (SDS-PAGE), empregado por ser relativamente simples, de baixo custo e capaz de detectar concentrações protéicas extremamente baixas e realizar identificação de 20 a 30 tipos diferentes de proteínas, incluindo as imunoglobulinas, ceruloplasmina, transferrina, hemopexina, albumina, antitripsina, haptoglobina, tripsina, dentre outras, a partir de diminutas quantidades de amostra (GORDON, 1995).

\section{CONCLUSÕES}

Os valores médios absolutos obtidos para proteínas séricas totais, albumina, alfa, beta e gamaglobulinas no sangue do cordão umbilical de cães ao nascimento foram $3,09 \pm 0,59 ; 1,51 \pm 0,38 ; 0,87 \pm 0,17$; $0,68 \pm 0,12$ e $0,03 \pm 0,01$, respectivamente.

Em todos os traçados eletroforéticos do soro do cordão umbilical de cães, foi observada uma pequena curva entre alfaglobulina ${ }_{2}$ e betaglobulina . $_{1}$

\section{REFERÊNCIAS}

BARSANTI, J.A. et al. Analysis of serum proteins, using agarose electrophoresis in normal dogs and in dogs naturally infected with Dirofilaria immitis. American Journal of Veterinary Research, Chicago v.38, n.7, p.1055-1058, 1977.

BUTLER, J.E. Bovine immunoglobulins: a review. Journal Dairy Science, Champaing, v.52, n.12, p.1895-1909, 1969.

ECKERSALL, P.D. Recent advances and future prospects for the use of acute phase proteins as markers of disease in animals. Revue de Médecine Vétérinaire, Toulouse, v.151 p.577584, 2000.

FELDMAN, B.C. et al. Veterinary hematology. 5.ed. Philadelphia: Lippincott Williams \& Wilkins, 2000. 1344p.

GLUCKMAN, E. et al. Hematopoietic reconstituition in a patient with Fanconi's anemia by means of umbilical-cord blood from an HLA-identical sibling. New England Journal of Medicine, Waltham, v.321, n.17, p.11741178, 1989.

GODOY, R.F. Estudo hematológico e proteínograma do sangue do funículo umbilical de eqüídeos neonatos. 2003. 64f. Dissertação (Mestrado em Cirurgia Veterinária)Faculdade de Ciências Agrárias e Veterinárias, Universidade Estadual Paulista, Jaboticabal.

GORDON, J.N. Electrophoresis of proteins in polyacrylamide and starch gels. New York, Elsever, 1995. 213p.

HARRUS, S. et al. Serum protein alterations in canine ehrlichiosis. Veterinary Parasitology, Amsterdam, v.66, p.241-249, 1996.

JAIN, N.C. Essentials of veterinary hematology. Philadelphia: Lea \& Febiger, 1993. p.349-380. 
KANEKO, J.J. et al. Clinical biochemistry of domestic animals. 5.ed. New York: Academic, 1997. p.932.

KEAY, G. Serum protein values from clinically normal cats and dogs determined by agarose gel electrophoresis. Research in Veterinary Science, London, v.33, n.3, p.343-346, 1982.

KUHL, S. et al. Reference values of chemical blood parameters in puppies during the first eight weeks of life. Deutsche Tierarztliche Wochenschrift, Hannover, v.107, n.11, p.438443, 2000.

MATTEWS, A.G. Serum protein electrophoresis in horses and ponies. Equine Veterinary Journal, London, v.14, n.4, p.322-324, 1982.

NAKAGE, A.P.M. et al. Determinação do volume corpuscular médio (VCM), concentração de hemoglobina corpuscular média (CHCM) e porcentagem de reticulócitos no sangue do cordão umbilical de cães neonatos. In: CONGRESSO BRASILEIRO DE MEDICINA VETERINÁRIA (CONBRAVET), 29., 2002, Gramado, RS. Anais... Gramado: Sociedade Brasileira de Medicina Veterinária, 2002. 1CD-Room.

NAKAGE, A.P.M. et al. Estudo das células sangüíneas do cordão umbilical de cães. In: CONGRESSO BRASILEIRO DE CLÍNICOS VETERINÁRIOS DE PEQUENOS ANIMAIS (Anclivepa), 24., 2003, Belo Horizonte, MG. Anais... Belo Horizonte: Associação Nacional de Clínicos Veterinários de Pequenos Animais, 2003. 1CD-Room.
NAKAGE, A.P.M. et al. Células-tronco no cordão umbilical de cães. In: CONGRESSO BRASILEIRO DE CLÍNICOS VETERINÁRIOS DE PEQUENOS ANIMAIS (ANCLIVEPA), 25., 2004, Gramado, RS. Anais... Gramado: Associação Nacional de Clínicos Veterinários de Pequenos Animais, 2004. 1CD-Room.

NAKAGE, A.P.M. et al. Tipo de parto e a hematologia do cordão umbilical de cães. Ciência Rural, Santa Maria, v.35, n.2, p.377-380, 2005

SEVELIUS, E.; ANDERSSON, M. Serum protein eletrophoresis as a prognostic marker of chronic liver disease in dogs. Veterinary Record, London, v.137, p.663-667, 1995.

TIZARD, I.R. Imunologia veterinária: uma introdução. 5.ed. São Paulo: ROCA, 1998. Cap.19, p.244-258.

VILMER, E. et al. HLA-mismatched cord blood transplantation in a patient with advanced leukemia. Transplantation, Paris, v.53, n.5, p.1155-1157, 1992.

WAGNER, J.E. et al. Transplantation of umbilical cord blood after mieloblative therapy: analysis of engraftment. Blood, New York, v.79, n.7, p.1874-1881, 1992.

ZANCO, N.A. Pesquisa anatômica das artérias e veias do funículo umbilical, sua ramificação e disposição na placenta de cães (Canis familiaris, Linnaeus, 1758). 1998. 187f. Tese (Doutorado em Medicina Veterinária) - Faculdade de Medicina Veterinária e Zootecnia, Universidade de São Paulo, São Paulo. 